\title{
Erratum to: Chemical analysis of bleach and hydroxide-based solutions after decontamination of the chemical warfare agent $O$-ethyl $S$-2-diisopropylaminoethyl methylphosphonothiolate (VX)
}

\author{
F. B. Hopkins • M. R. Gravett • A. J. Self • M. Wang • \\ H. C. Chua • H. S. Nancy Lee • J. T. A. Jones • \\ C. M. Timperley $\bullet$ J. R. Riches
}

Received: 8 April 2014 / Accepted: 8 April 2014 /Published online: 9 May 2014

(C) Springer-Verlag Berlin Heidelberg 2014

\section{Erratum to: Analytical and Bioanalytical Chemistry \\ DOI 10.1007/s00216-014-7674-2}

The authors would like to call your attention to the fact that two author names (C. Hoe-Chee and N. Lee Hoi Sim) were misspelled in the original publication: they should be H. C. Chua and H. S. Nancy Lee.

Published in the topical collection Analysis of Chemicals Relevant to the Chemical Weapons Convention with guest editors Marc-Michael Blum and R. V. S. Murty Mamidanna.

The online version of the original article can be found at http://dx.doi.org/ 10.1007/s00216-014-7674-2.

F. B. Hopkins · M. R. Gravett · A. J. Self · J. T. A. Jones •

C. M. Timperley $\cdot$ J. R. Riches $(\bowtie)$

Detection Department, Defence Science and Technology Laboratory

(Dstl), Porton Down, Salisbury, Wiltshire SP4 0JQ, UK

e-mail: jriches@dstl.gov.uk

M. Wang $\cdot$ H. C. Chua $\cdot$ H. S. N. Lee

DSO National Laboratories, 20 Science Park Drive, Singapore,

Singapore 118230 